\title{
UTILIZING CANVA AS DIGITAL TOOLS TO TEACH GRAMMAR IN REMOTE LEARNING PERIOD
}

\author{
Eka Nurhidayat \\ English Language Education Program, Universitas Majalengka \\ ekanurhidayat@unma.ac.id
}

\begin{abstract}
The use of a digital tool in teaching and learning has significantly increased due to the remote learning period. Digital tools in education may be viewed as interference to learning. Still, its role in education is to increase students' motivation and engagement, enhance visual skills, improve students' interaction and collaboration abilities with their peers, and apply digital values in a real-world situation. This study aims to discuss the use of Canva as a digital tool in teaching grammar in the remote learning period. Ten thirdyear students were selected as the participant of this study. The instruments are observation and interview. The design of this study was a descriptive study. The results showed that Canva enhances students' visual skills, interactions, motivation, and engagement in learning grammar.
\end{abstract}

Keywords: Canva, Digital tools, teaching grammar

\section{Introduction}

Due to the remote learning period, digital tools in teaching and learning have increased significantly. While some may view digital tools in education as a hindrance to learning, their role is to increase students' motivation and engagement. It also improves students' visual skills, improves students' interaction and collaboration abilities with their peers, and enables them to apply digital values in real-world situations. Language education is impacted by technology in the skill areas of listening, speaking, reading, and writing, as well as across all competencies (grammatical, sociolinguistic, discourse, and strategic). Given its role in all of these areas, technology-assisted grammar instruction presents unique challenges and opportunities. Before delving into the considerations and options for teaching grammar through technology, it's necessary to define a few key terms used throughout this entry (Bikowski, 2018).

Dontcheva-Navratilova (2012) emphasizes the importance of meaningful communication within language structure when she defines Grammar as the rules and principles governing the form and meaning of words, phrases, clauses, and sentences. Proper Grammar is a necessary component of advanced language proficiency. Understanding how words work and how they fit together is critical for effectively using foreign words. Grammar is always going to be a necessary component of language learning and should not be overlooked. Even when emphasizing vocabulary acquisition, ways can and should incorporate Grammar into the learning process. By making Grammar learning appealing, efficient, and effective, the right strategies and technologies can overcome any objections about possible boredom or difficulty. College students prefer to participate in their activities via technology in the current climate. Numerous researchers (Brenes \& Rivero, 2018; Wiyaka et al., 2018) emphasize the importance of technology in language teaching because it can boost students' motivation.

Canva App is one piece of technology that the teacher can utilize. Canva as a teaching tool. Canva can motivate students to write by providing stimuli in photographs, graphics, images, photo filters, free icons, shapes, and hundreds of fonts (Canva, n.d.). Canva, the visual media provided by technology, was identified as a potential means of increasing students' opportunities to participate actively in writing processes. Tinio (2002) notes that Information and 
Communication Technology (ICT) equips students with digital-age literacy, inventive thinking, higher-order thinking skills, effective communication, and high productivity. Students comprehension of Grammar improves when they use Canva as a technology medium.

Additionally, they learn how to incorporate technology into language learning. Additionally, it is believed that learning a foreign language is a pleasurable activity for students. Canva provides excellent benefits for increasing their motivation. The majority of students stated that using Canva to assist them in learning grammar benefits them by providing images, color images, photos, fonts, and graphics. They believed that using Canva increased their creativity when it came to learning grammar. They discovered that using Canva made the writing process more manageable. It became effortless to communicate their ideas via Canva, and readers quickly understood the messages. Finally, students indicated that they felt more motivated to write and that using Canva helped alleviate their anxiety. Students view Canva as a valuable and practical tool for promoting their writing in general.

Numerous studies have investigated the use of technology in the EFL context. Haswani (2014) researched the role of Technology in the EFL classroom. The present study aimed to expand on the research of innovative board technology. According to the survey, EFL teachers have a favorable attitude toward the smartboard. The smartboard is especially beneficial for English language classes because it enables teachers to use authentic and visually appealing materials with their students. Students report having a favorable attitude toward using the smartboard. Students are not confused by the smartboard; however, they lack the necessary skills to use it. By considering students' attitudes and challenges, teachers can improve their instruction by developing students' technology skills and positive attitudes. Mariani (2018) presented how a digital application can teach and learn English writing skills using mobile phones and computers. One of the digital educational apps that can help in writing is Canva. The objective of this article is for college students who are studying Basic Writing. Applying this educational application is expected that the college students' motivation in writing is getting higher. The present study endeavor to describe the utilizing of Canva as a digital tool in teaching grammar in the remote learning period. In this study, previous literature related to the use of technology in teaching grammar and how lectures and students apply Canva in grammar instruction.

\section{Research Methodology}

This qualitative study describes Canva as a digital tool in teaching and learning in the remote learning period. This study was conducted at English Education Study Program in Majalengka, West Java. Ten third-year students were selected as the participants of this study. The data were obtained through classroom observation. The observation was used to get data about the implementation of Canva as a digital tool in teaching and learning grammar at EFL remote learning.

Then, semi-structured interviews were conducted to recheck and complete the data obtained from observation. This kind of interview allows the researcher to control the interview (Creswell, 2012). The interviews consisted of some questions related to technology integration in EFL remote learning. The data gathered from the questionnaire were coded, categorized, and interpreted. Then, the results of the interview were transcribed, then coded, organized, and analyzed.

\section{Findings and Discussion}

\section{Understanding of Canva}

Melanie Perkins discovers Canva. She is the co-founder and CEO of Canva, an online platform that makes graphic design accessible to everyone. It was founded in 2012 and launched in 2013, with over one million users creating over 7 million designs within 14 months of launch. In October 2014, the iPad app was released, combining a simple drag-and-drop design interface with a library of over one million photos, graphics, and fonts.

According to Neltner (2015), Canva is an "online graphic design program that can be used to 
create everything from blog graphics to Facebook headers, posters, and flyers." She added that Canva is both free and user-friendly, as it is a drag-and-drop image editor, and users can also share their creations via PDF or JPEG. Canva is revolutionizing the way the world creates beautiful designs. We have over a million images to choose from, thousands of customizable layouts, and simple photo editing. We are capable of collaborating with anyone, at any time, and from any location. Anyone, including non-designers, can use Canva to create designs. Canva's vision is to provide an innovative tool that enables individuals to create beautiful and professional designs without the friction of expensive and time-consuming platforms such as Photoshop or In Design. It takes the thought process from learning the user interface, allowing you to spend more time creating. It has established a strong presence across social media, marketing, business, entrepreneurship, and education. Canva enables anyone to communicate effectively through the use of a variety of designs. It can create work presentations, pitch proposals, and graphics for blogs and social media posts. Additionally, it provides you with the tools necessary to create visually stunning graphics that effectively communicate your message.

\section{The Implementation of Canva to Skill}

Canva is the best PDF software for teaching that came in second place out of five applications, including Quiz Faber, Canva, What2Learn, Tutor.Room.net, and Grade Keeper. Thus, the writer chose Canva as the application that will assist students in learning grammar. Canva is used to create some fantastic graphics without advanced software such as Photoshop or Illustrator. Not only the teacher but also the students can use canva. As a result, this application suggests ways to improve the teaching and learning process, particularly writing.

\section{Sample of Material}

Here, the teacher instructs college students on Basic English Grammar through the use of Canva. Their proficiency is intermediate. Thus, as part of their final project, college students are expected to create a poster related to Word Classes, Phrase, Clause, and a sentence using Canva. Additionally, they collaborate with their friends to develop and discuss a related topic.
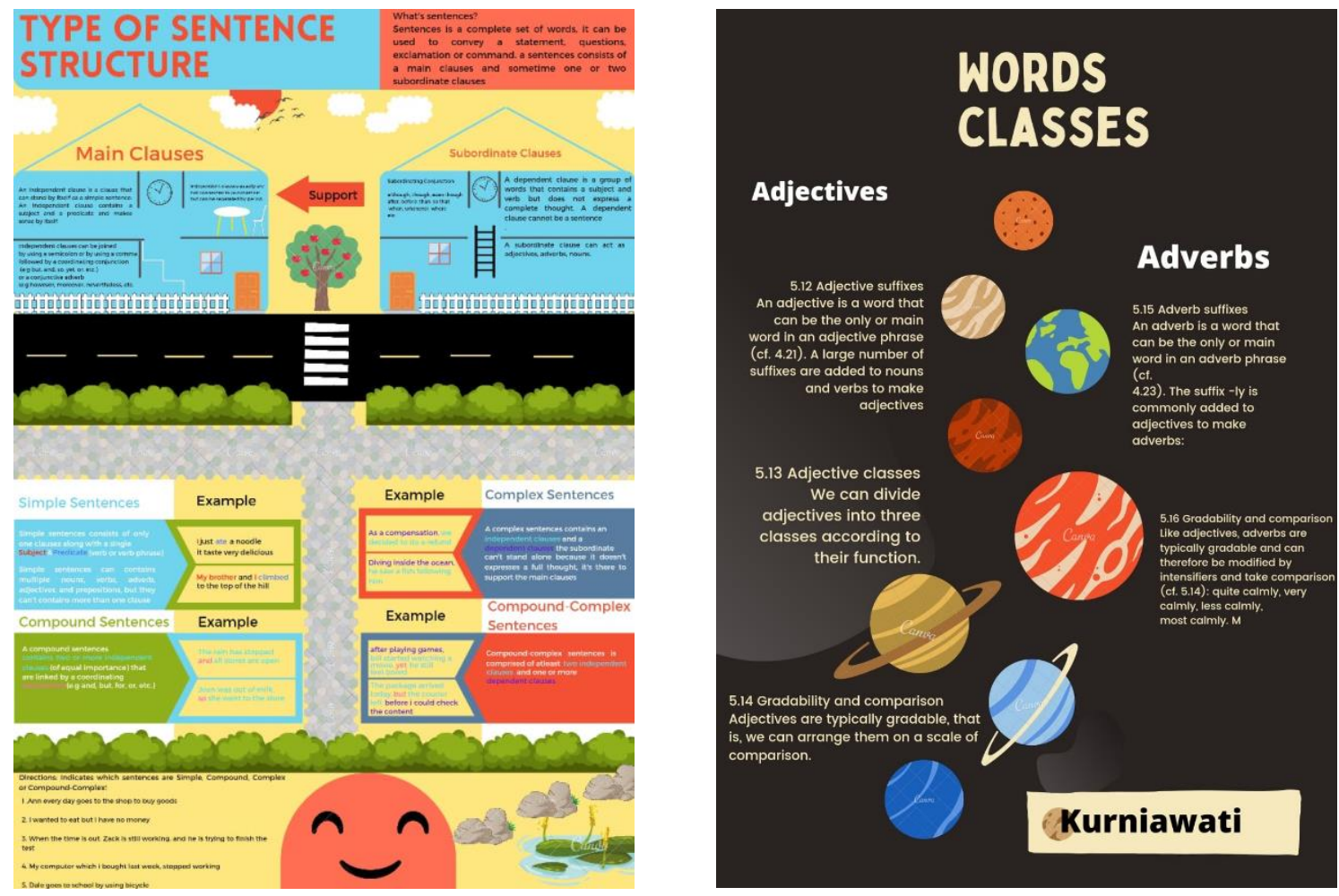

The Procedure of Teaching Grammar by using Canva

a. Pre-Teaching Activity 
This is the initial activity that should be used to teach Grammar. Activities that involve planning to generate ideas. These activities aid in the process and product planning. The teacher introduces a topic and displays a picture created using the Canva App in this activity. The teacher intended to communicate to the students to create a poster about "Word Classes." The teacher then divided the class into five groups of four students each. To participate in the class, they must create a poster on a chosen topic about word classes. There are a total of eight-word classes. Each group is required to create a unique poster.

b. Whilst Activity

Throughout the activity, the teacher can request that the students develop their ideas into clear explanations. Throughout the activities, the teacher can monitor each student individually.

c. Post-Teach Activity

The teacher can check the work of college students in post-activity. The teacher can use this activity to review the explanation, example, and other content. Then, after the teacher corrects their errors, the students rewrite the content. To improve your chances of becoming a good poster.
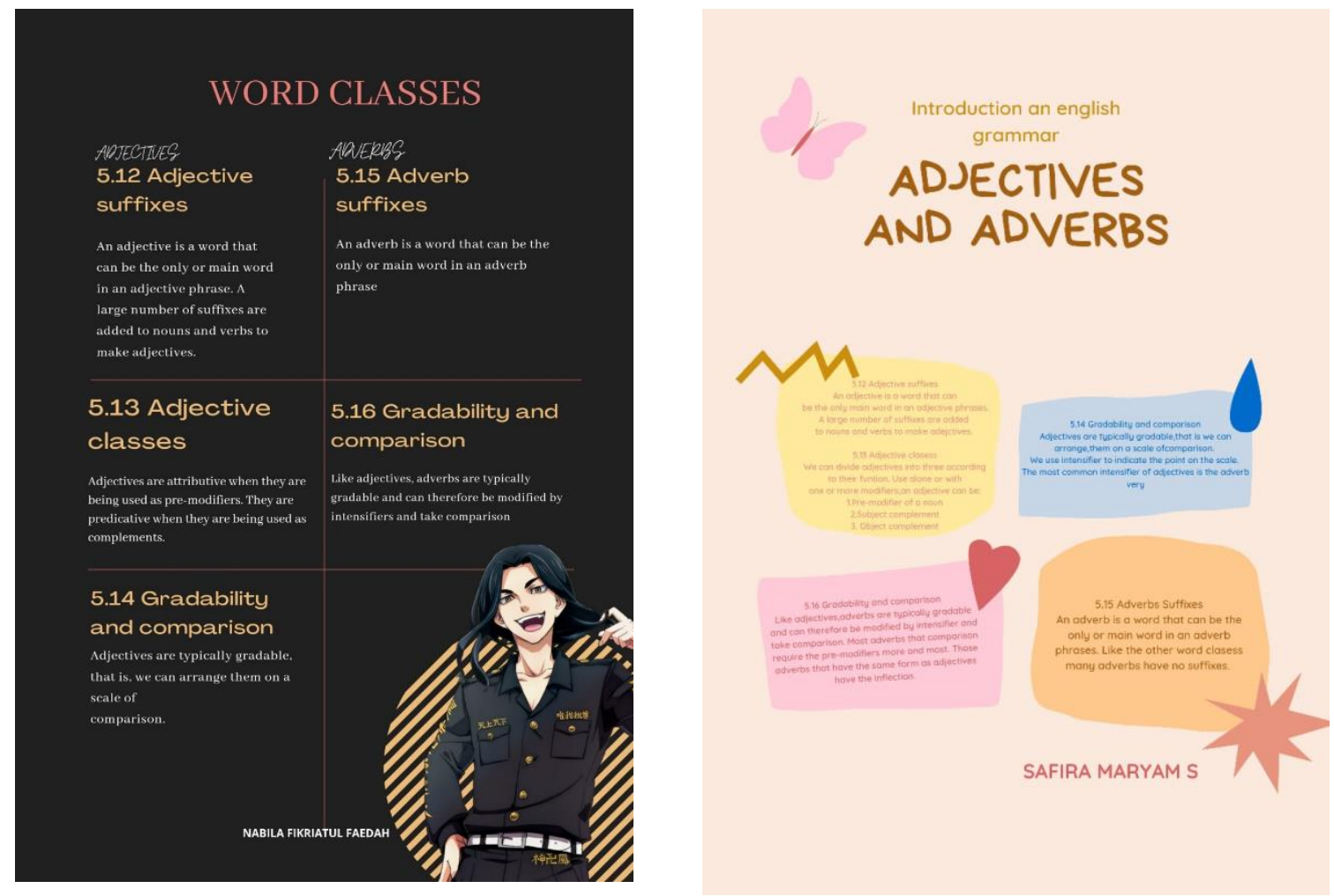

\section{Conclusion}

Grammar will always be an integral part of language learning and should not be neglected. Even when vocabulary acquisition is prioritized, ways can and should be found to incorporate Grammar into the learning process. By making grammar instruction appealing, efficient, and practical, the appropriate strategies and technologies can overcome any concerns about boredom or difficulty. In today's climate, college students prefer to participate in their activities via technology. However, students' grammar ability remains low, owing to a lack of motivation and the teacher's continued use of traditional strategies and media. Thus, as a means of teaching grammar, the teacher should employ media, as media plays a critical role in teaching and learning. However, in this era, technology plays a crucial role. The solution is achieved through the use of media technology. They use Canva as a technology medium that enables college students to develop and improve their grammar comprehension. Additionally, they learn how to 
incorporate technology into language learning. Additionally, make it simple for them to express their emotions while learning Grammar and encourage them to think creatively.

\section{References}

Bikowski, D. (2018). Technology for Teaching Grammar. The TESOL Encyclopedia of English Language Teaching, 1-7. https://doi.org/10.1002/9781118784235.eelt0441

Creswell, J. W. (2012). Educational Research: Planning, Conducting, and evaluating Quantitative and Qualitative research (4th Ed). Pearson.

Dontcheva-Navratilova, O. (2012). Grammar and Discourse. The Encyclopedia of Applied Linguistics. https://doi.org/10.1002/9781405198431.wbeal0464

Haswani, F. (2014). the Role of Technology in Efl Classroom. IJEE (Indonesian Journal of English Education), 1(2), 107-118. https://doi.org/10.15408/ijee.v1i2.1303

Mariani. (2018). The Use of CANVA in Teaching Writing for College Students. Gastrointestinal Endoscopy, 10(1), 279-288. http://dx.doi.org/10.1053/j.gastro.2014.05.023\%0Ahttps://doi.org/10.1016/j.gie.2018.04.01 3\%0Ahttp://www.ncbi.nlm.nih.gov/pubmed/29451164\%0Ahttp://www.pubmedcentral.nih. gov/articlerender.fcgi?artid=PMC5838726\%250Ahttp://dx.doi.org/10.1016/j.gie.2013.07.0 22

Neltner, H. 2015. Using Canva and Powtoon to Promote your Library Program. School Librarian's Workshop, 35(5), 24-25.

Ruiz Brenes, M. del C., \& Hernández Rivero, V. M. (2018). La incorporación y uso de las TIC en Educación Infantil. Un estudio sobre la infraestructura, la metodología didáctica y la formación del profesorado en Andalucía. Pixel-Bit, Revista de Medios y Educación, 5(52), 81-96. https://doi.org/10.12795/pixelbit.2018.i52.06

Tinio, V. L. 2002. Survey of information \& communication technology utilization in Philippine public high $\quad$ schools. $\quad$ Retrieved from http://www.fited.org/downloads/ICT\%20Utilization\%20Survey .pdf.

Wiyaka, ., Mujiyanto, J., \& Rukmini, D. (2018). Students' Perception on the Usefulness of ICT Based Language Program. English Language Teaching, 11(2), 53. https://doi.org/10.5539/elt.v11n2p53 